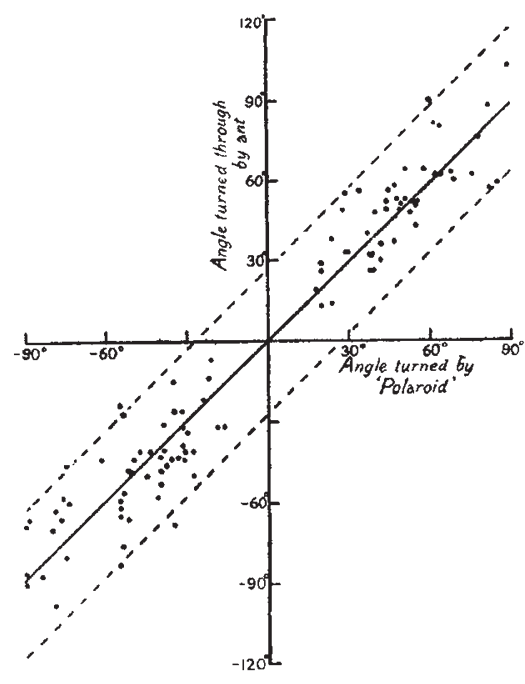

orientation. The angle between the axes of adjacent ommatidia is about $8^{\circ}$.

(3) The optical system of the ant's compound eye was examined with reference to polarized light. The results are complex and merit a discussion too long to be included here.

It seems reasonable to suppose that the above results demonstrate both the sensitivity of ants to the plane of polarization of light and their ability to orientate themselves by means of this sensitivity. While neither the mechanism nor the importance of this property in the field is known, it is thought that both the methods and results of the preliminary demonstration may be of interest to workers beyond the rather limited field of ant behaviour.

D. M. Vowles

Dept. of Zoology and Comp. Anatomy,

University Museum,

Oxford.

Sept. 26.

${ }^{1}$ Von Frisch, K., Experientia, 5, 142 (1949). See review by Thorpe, W. H., Nature, 164, 11 (1949)

${ }^{2}$ Santschi, F., Mem. Soc. vaud. Sci. Nat. 1923, 137 (1923).

\section{Ciliary Feeding Mechanisms in Anuran Larvæ}

THE feeding mechanism and mode of feeding of tadpoles of Xenopus loevis have been described, notably by Bles $^{1}$ and by Weisz ${ }^{2}$. These workers agree in postulating a ciliary mechanism; but their accounts of the nature and functioning of this mechanism differ widely. Bles recognized a ciliated pharyngeal groove lying along the outer margin of the branchial chamber on each side as the main foodcollecting channel. Weisz, on the other hand, holds that food particles never reach the branchial chambers, and makes no mention of the ciliated paths which lie at their outer margins and converge on the œesophagus. He states that the middle region if the pharyngeal floor (called by him the "pha yngobranchial tract" and said to be ciliated) is respr insible for creating ciliary currents by which food pirticles pass backwards into the alimentary canal.

Recent work here has shown the earlier account of Bles to be correct. In particular, it has not been found possible to demonstrate the presence of cilia on the pharyngo-branchial tract, though rhythmical movements of this area during gulping may serve to direct incoming food particles into the branchial pouches. On the other hand, the ciliated pharyngeal grooves and their subsidiary channels in the branchial chambers can be demonstrated very convincingly by the use of finely powdered carmine, or colloidal graphite $^{3}$, especially the latter. They are easily visible through the transparent wall of the pharynx within a fow minutes of adding the material to water in which the tadpoles are living.

The feeding mechanism of these tadpoles has been compared with that of Amphioxus and the ammocote larva of the Cyclostomata. These organisms, however, exemplify ciliary feeding in the fullest sense illustrated by many invertebrates, that is, both the initial feeding current and the local internal collecting currents are created by ciliary action. In the larval Xenopus, however, the feeding stream is dependent on the activity of typical masticatory muscles, the action of which sustains the continuous gulping movements so characteristic of these tadpoles. The ciliary feeding of Xenopus larvæ thus combines a ciliary mechanism for food collection and subsequent transportation of a type commonly found in invertebrates or sedentary forms with a masticatory mode of ingestion characteristic of active Gnathostomata. The ciliary part of this apparatus would appear to be an adaptation for microphagy, and may be correlated with absence of peristalsis in the œesophagus. The larval stomach is modified for packing the thin mucous strings charged with food, and seems to have no obvious digestive function. No food particles are liberated in it from the mucus.

Barrington ${ }^{4}$, after studying the development and histology of the stomach of larvæe of Rana temporaria and Bufo bufo, suggested feeding in Anuran tadpoles is fundamentally microphagous. Preliminary experiments with the tadpoles of these two forms show that their feeding mechanisms are essentially similar to that of Xenopus. The pharynx is, of course, relatively smaller and less specialized, and 'gulping' is much more rapid ; but the particles liberated by the buccal rasp, and particles in suspension in the water, enter the mouth by the gulping activity of the masticatory muscles, and are conveyed to the cesophagus in mucus by ciliary action. As in Xenopus larvæ, the stomach serves to pack the mucous strings. Particles of colloidal graphite in the size-range $0.2-2.0 \mu$ are efficiently extracted from water by both these tadpoles, and appear embedded in mucous strings in pharynx, œsophagus, and stomach within a fow minutes of the tadpoles being placed in the suspension. Moreover, tadpoles of $R$. temporaria and $B$. bufo have been successfully reared through metamorphosis on a diet of particles of dried liver which would pass through a 200-mesh-per-inch sieve. It may also be noted that Kratochwill ${ }^{5}$ has described a ciliary foodcollecting mechanism in the larvæ of Rana agilis.

I am indebted to Messrs. Acheson Colloids, Ltd., of London, S.W.1, for a supply of 'Aquadag' colloidal graphite.

\section{Department of Natural History,}

\section{J. M. DODD}

University, St. Andrews.

$$
\text { Sept. } 27 .
$$

Bles, E. J., Trans. Roy. Soc. Edin., 41, Pt. 3 (1905).

2 Weisz, Paul B., J. Morph., 77, No. 2 (1945)

3 Jorgensen, C. B., Nature, 163, 4154 (1949)

4 Barrington, E. J. W., Proc. Zool. Soc. Lond., 116, Pt. 1 (1946).

${ }^{5}$ Kratochwill, K., Z. f. wiss. Zool., 144. 